\title{
Spectrophotometric determination of tizanidine and orphenadrine via ion pair complex formation using eosin $Y$
}

\author{
Mohamed I Walash, Fathalla F Belal, Manal I Eid and Samah Abo El Abass Mohamed
}

\begin{abstract}
A simple, sensitive and rapid spectrophotometric method was developed and validated for the determination of two skeletal muscle relaxants namely, tizanidine hydrochloride (I) and orphenadrine citrate (II) in pharmaceutical formulations. The proposed method is based on the formation of a binary complex between the studied drugs and eosin $\mathrm{Y}$ in aqueous buffered medium (pH 3.5). Under the optimum conditions, the binary complex showed absorption maxima at $545 \mathrm{~nm}$ for tizanidine and $542 \mathrm{~nm}$ for orphenadrine. The calibration plots were rectilinear over concentration range of $0.5-8 \mu \mathrm{g} / \mathrm{mL}$ and $1-12 \mu \mathrm{g} / \mathrm{mL}$ with limits of detection of $0.1 \mu \mathrm{g} / \mathrm{mL}$ and $0.3 \mu \mathrm{g} / \mathrm{mL}$ for tizanidine and orphenadrine respectively. The different experimental parameters affecting the development and stability of the complex were studied and optimized. The method was successfully applied for determination of the studied drugs in their dosage forms; and to the content uniformity test of tizanidine in tablets.
\end{abstract}

\section{Introduction}

Tizanidine hydrochloride or 5-Chloro-N-(2-imidazolin2-yl)-2,1,3-benzothiadiazol-4-ylamine hydrochloride(1-3), is a centrally acting skeletal muscle relaxant. It is an $\alpha 2-$ adrenergic agonist that acts mainly at spinal and supraspinal levels to inhibit excitatory interneurones. It is used for the symptomatic relief of spasticity associated with multiple sclerosis or with spinal cord injury or disease. It is also used in the symptomatic treatment of painful muscle spasm associated with musculoskeletal conditions [1]. The United States Pharmacopoeia (USP) recommends HPLC method for determination of tizanidine (I) in the raw material and tablets [4]. Additionally, a number of methods like spectrophotometry [5-12], voltammetry [13-15], GC [16,17], TLC [18-20] and HPLC [12,18,21-24], have been reported in the literature for the determination of tizanidine hydrochloride.

Orphenadrine citrate (II) or N, N-dimethyl-2-[(2methylphenyl) phenylmethoxy] ethanamine [3], is employed as skeletal muscle relaxant [2]. The recommended method for determination of orphenadrine in USP [4] is HPLC while the British Pharmacopoeia (BP)

\footnotetext{
* Correspondence: manal_eid@yahoo.com

Department of Analytical Chemistry, Faculty of Pharmacy, University of Mansoura, Mansoura, 35516, Egypt
}

recommends a potentiometric titration procedure for its assay of the raw material [25]. Several methods for determination of Orphenadrine in pharmaceutical formulations have been described, via spectrophotometry [26-30], GC [31], capillary electrophoresis [32-35], TLC [36] and HPLC [37-39].

The formation of complexes between eosin $\mathrm{Y}$ as an ion pairing agent and many pharmaceutical compounds for their spectrophotometric or spectrofluorimetic analysis with or without metal ions has been frequently investigated [40-45].

The method suggested is devoted to study the formation of a binary complex between each of the studied drugs and eosin $\mathrm{Y}$ in an attempt to develop a simple, sensitive and accurate extraction- free spectrophotometric method for the determination of the studied drugs in their pharmaceutical preparations.

\section{Experimental \\ Apparatus}

A Shimadzu recording Spectrophotometer (UV-1601, P/ N 206-67001) with 1-cm matched cells was used.

\section{Materials and reagents}

All materials used were of Analytical Reagent grade, and doubly distilled water was used throughout the work. 
-Tizanidine hydrochloride and orphenadrine citrate were kindly provided by Sigma Pharmaceutical Company, Cairo, Egypt, they were used as received.

- Eosin Y (Merck, Darmstadt, Germany), $4 \times 10^{-3} \mathrm{M}$ aqueous solution was prepared in distilled water.

- Acetic acid and anhydrous sodium acetate (Merck, Darmstadt, Germany).

- Acetate buffer, 0.4 $\mathrm{M}$ was prepared by mixing various volumes of $0.4 \mathrm{M}$ acetic acid and $0.4 \mathrm{M}$ sodium acetate solutions to obtain the required $\mathrm{pH}$ value.

-Sirdalud ${ }^{\circledR}$ Tablets (labeled to contain $2 \mathrm{mg}$ and $4 \mathrm{mg}$ of tizanidine hydrochloride), Norflex ${ }^{\circledR}$ Tablets (labeled to contain $100 \mathrm{mg}$ of orphenadrine citrate) and Norflex ${ }^{\circledR}$ ampoules (labeled to contain $30 \mathrm{mg}$ of orphenadrine citrate $/ \mathrm{ml}$ ) were obtained from commercial sources in the local market.

\section{Standard solutions}

- Stock solutions of $100.0 \mu \mathrm{g} / \mathrm{mL}$ for (I) or (II) drugs were prepared by dissolving $10.0 \mathrm{mg}$ of either drug in $100 \mathrm{~mL}$ of distilled water. These solutions were stable for at least a week when kept in the refrigerator and protected from light. More dilute solutions were obtained by appropriate dilution.

\section{Procedures for calibration graph}

Transfer accurately measured aliquots of the stock solution in the concentration range shown in table 1 into a series of $10 \mathrm{~mL}$ volumetric flasks and diluted to about $7 \mathrm{~mL}$ with distilled water. $1 \mathrm{~mL}$ for (I) and 0.7 $\mathrm{mL}$ for (II) of $4 \times 10^{-3} \mathrm{M}$ of eosin Y solution was added to each flask, and the solutions were mixed well

Table 1 Analytical parameters for the analysis of the studied drugs by the proposed spectrophotometric method

\begin{tabular}{ccc}
\hline Parameter $^{(\mathbf{a})}$ & Tizanidine(I) & Orphenadrine(II) \\
\hline Wavelength(nm) & 545 & 542 \\
Concentration range $(\boldsymbol{\mu g} / \mathbf{m L})$ & $0.5-8$ & $1-12$ \\
Limit of detection (LoD) $(\boldsymbol{\mu g} / \mathbf{m L})$ & 0.1 & 0.3 \\
Limit of quantification(LoQ) & 0.26 & 0.95 \\
$(\boldsymbol{\mu g} / \mathbf{m L})$ & & \\
Correlation coefficient & 0.9999 & 0.9998 \\
Slope & 0.12 & 0.09 \\
Intercept & 0.11 & 0.032 \\
$\mathbf{S}_{\mathbf{y} / \mathbf{x}}$ & $5.43 \times 10^{-3}$ & 0.013 \\
$\mathbf{S}_{\mathbf{a}}$ & $3.2 \times 10^{-3}$ & $8.84 \times 10^{-3}$ \\
$\mathbf{S}_{\mathbf{b}}$ & $7.06 \times 10^{-4}$ & $1.29 \times 10^{-3}$ \\
$\mathbf{R S D}, \%$ & 1.20 & 1.60 \\
$\%$ Error & 0.45 & 0.64 \\
$\boldsymbol{\varepsilon}(\mathbf{I} / \mathbf{m o l} / / \mathbf{c m})$. & $4.26 \times 10^{4}$ & $4.63 \times 10^{4}$ \\
\hline
\end{tabular}

(a) Sy/x: standard deviation of the residuals; $\mathrm{S}_{\mathrm{b}}$ : standard deviation of the slope,

$\%$ Error $=\% \mathrm{RSD} / \sqrt{ } \mathrm{n} ; \mathrm{Sa}$, standard deviation of the intercept; and $\varepsilon$, molar absorptivity. before the addition of $2 \mathrm{~mL}$ of $0.4 \mathrm{M}$ acetate buffer ( $\mathrm{pH}$ 3.5). the solution completed with distilled water to the mark. The absorbance was measured at 545 or 542 $\mathrm{nm}$ for (I) or (II) respectively against an appropriate reagent blank prepared simultaneously. To get the standard calibration graphs, the values of the absorbance were plotted against the final concentration in $\mu \mathrm{g} / \mathrm{mL}$, alternatively the regression equations were derived.

\section{Procedures for determination of the studied drugs in dosage forms \\ Tablets}

An accurately weighed quantity of the mixed contents of 10 pulverized tablets equivalent to $10.0 \mathrm{mg}$ of either drug were transferred into $100 \mathrm{~mL}$ volumetric flasks, and completed to the mark with distilled water. The contents of the flask were sonicated for $15 \mathrm{~min}$ and filtered, and the above procedure was followed, the nominal contents were calculated either from the previously plotted calibration graphs or using the corresponding regression equations.

\section{Ampoules}

An accurately measured volume of the mixed contents of 10 ampoules equivalent to $10.0 \mathrm{mg}$ of orphenadrine citrate were transferred into $100 \mathrm{~mL}$ volumetric flask, and diluted to $100 \mathrm{~mL}$ with distilled water. The above procedure was followed; the nominal contents were calculated adopting the standard addition method.

\section{Determination of the stoichiometry of the reaction}

The stoichiometry of the reaction between the studied drugs and eosin $\mathrm{Y}$ was determined by continuous variation method (Job's method) [46], using equimolar solutions $\left(1.5 \times 10^{-3} \mathrm{M}\right)$ for (I) and $\left(1 \times 10^{-3} \mathrm{M}\right)$ for (II) of the drug and the reagent.

\section{Results and Discussion}

Eosin $Y$ was chosen as an ion-pairing agent with the aim of obtaining stable and water soluble ion pairs whose absorbance would be measured accurately. The described method has the advantage of being simple, fast, accurate, and precise for determining tizanidine and orphenadrine in their pharmaceutical formulations without interference from common excipients. Moreover, it is less time-consuming and does not require various elaborate treatment or tedious extraction procedures. These, in addition to the satisfactory sensitivity and simplicity make the method suitable for routine analysis in quality control laboratories.

The proposed method is based on binary complex formation between the studied drugs and eosin Y. These complexes were probably formed via electrostatic interaction between the most basic center in the drug 


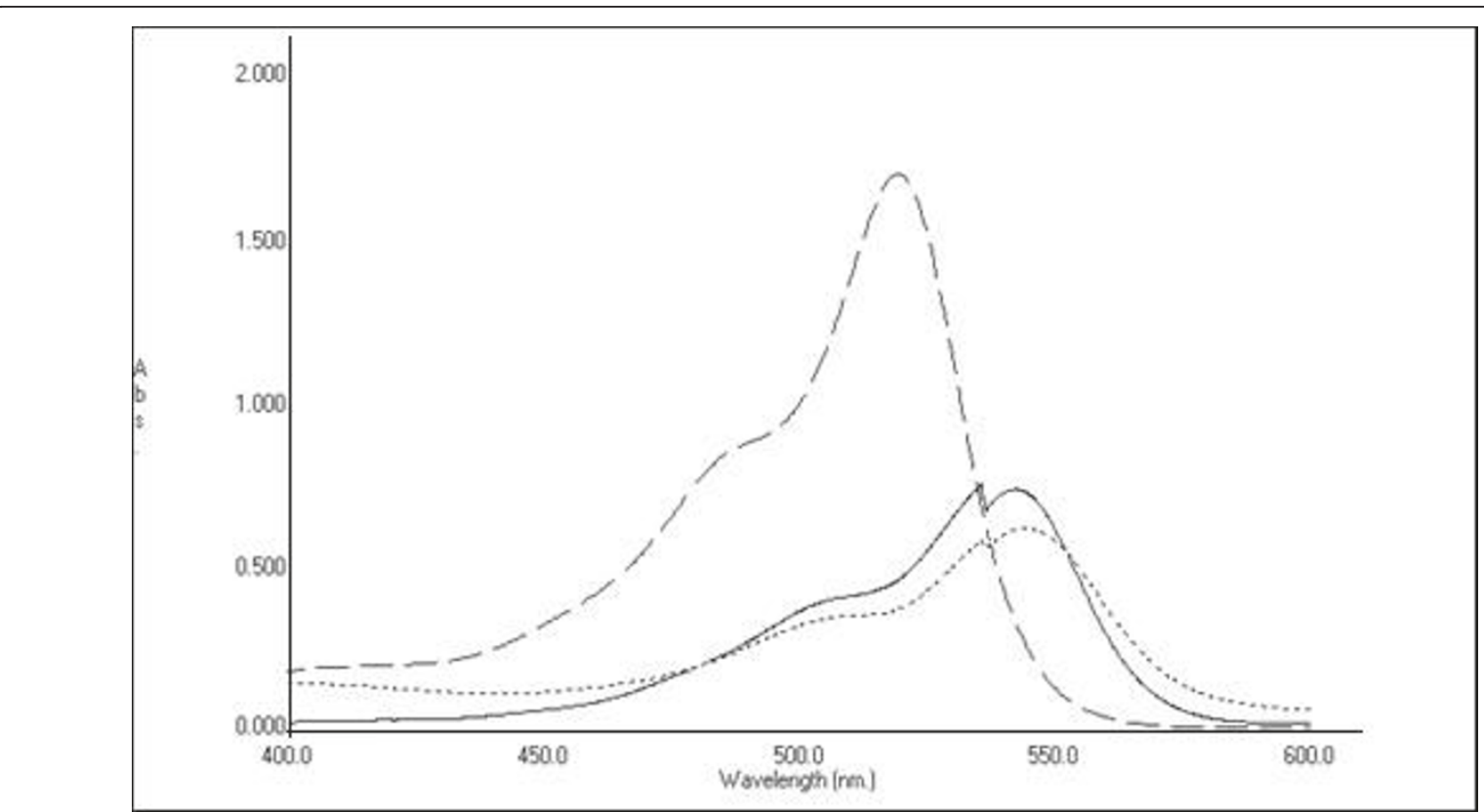

Figure 1 Absorption spectra. (A) Blank eosin $Y\left(4 \times 10^{-3} \mathrm{M}\right)$ in water $\left(_{-} \_\right.$). (B) Eosin $Y$ binary complex with tizanidine hydrochloride $(5 \mu \mathrm{g} /$ $\mathrm{mL})$ in water at $\mathrm{pH} 3.5(-)$. (C) Eosin $\mathrm{Y}$ binary complex with orphenadrine citrate $(5 \mu \mathrm{g} / \mathrm{mL})$ in water at $\mathrm{pH} 3.5(. . .$.$) .$

molecule (amino group) and the carboxylate anion of the dye. This primarily occurs in an acidic solution, increasing the electron delocalization of eosin and producing a bathochromic shift of the dye about $30 \mathrm{~nm}$ (Figure 1), Applying Job's method (Figure 2), it was found that, the reaction proceeds in the ratio of $1: 2$ of drug to eosin for tizanidine as it has two basic centers and while 1:1 for orphenadrine as it has one basic center of drug to eosin Y, the proposed mechanism of the reaction pathway is shown in Figure 3.
Due to the slight solubility of complexes formed with eosin $\mathrm{Y}$ in aqueous acidic solutions, it was difficult for the produced color to be accurately and precisely measured. Therefore, several trials for solving this problem were conducted, Via extraction with organic solvent [47] or addition of nonionic surfactant such as methyl cellulose to solubilize and stabilize the formed complex were attempted [40,41].

Methyl cellulose and tween 80 were attempted to prevent complex precipitation, however the reproducibility

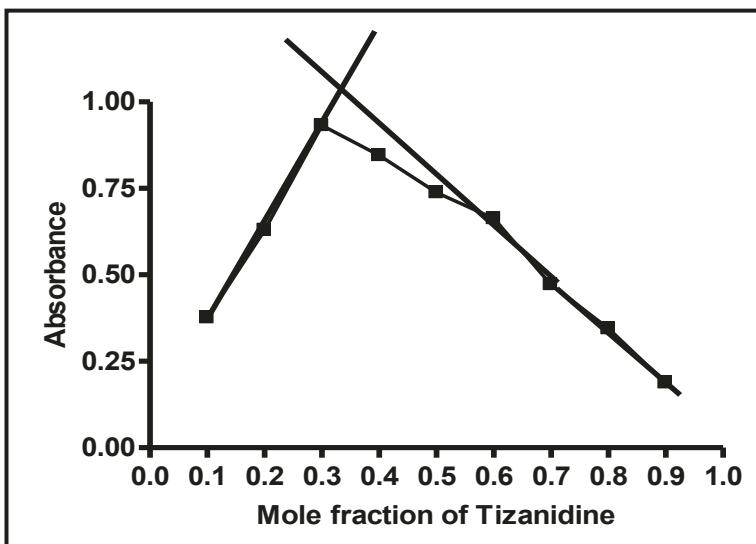

(A)

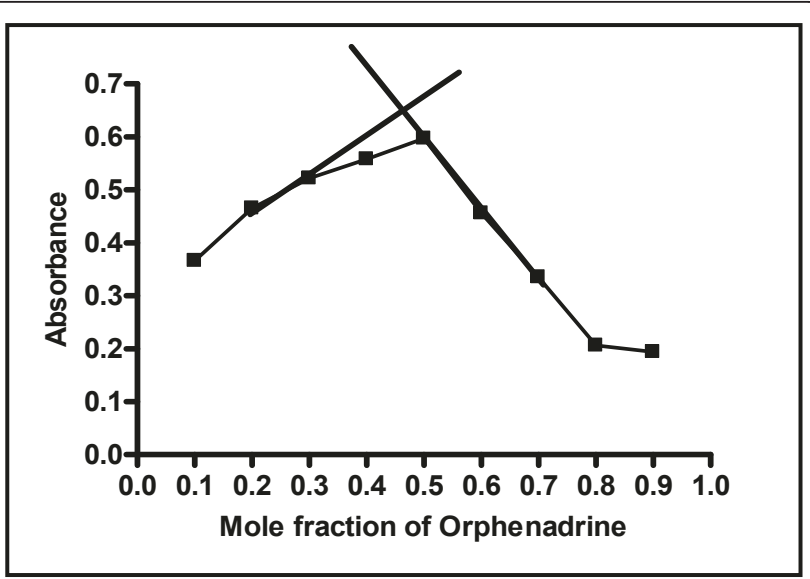

(B)

Figure 2 Continuous variation plots for the ion association complexes. (A) Tizanidine hydrochloride $\left(1.5 \times 10^{-3} \mathrm{M}\right)$ with eosin $\mathrm{Y}\left(1.5 \times 10^{-3}\right.$ M). (B) Orphenadrine citrate $\left(1 \times 10^{-3} \mathrm{M}\right)$ with eosin $\mathrm{Y}\left(1 \times 10^{-3} \mathrm{M}\right)$. 

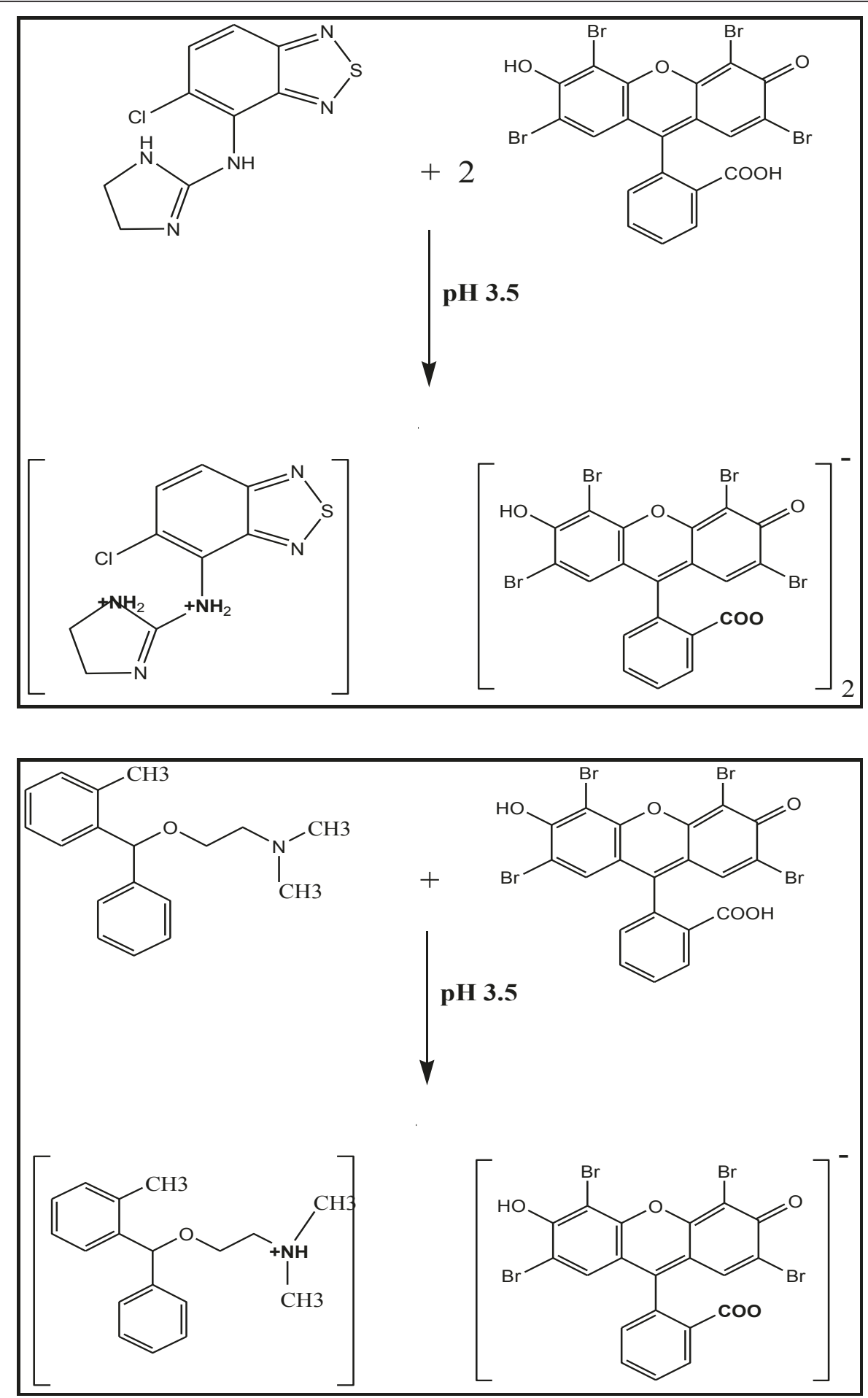

Figure 3 Proposed mechanisms for the reaction between tizanidine and orphenadrine with eosin Y. (A) Proposed mechanism for the reaction between tizanidine and eosin Y. (B) Proposed mechanism for the reaction between orphenadrine and eosin Y.

was adversely affected; therefore, the method described by El-Brashy et al [42] was adopted. This method is based on keeping the sample concentration at maximum dilution before adding the dye solution at neutral solution, and mixing well before the addition of the acidic buffer. Applying this procedure, the complex stability was greatly increased, and prevention of precipitate formation with maximum precision was achieved. 
The order of addition of the reagent and buffer was essential for good precision. The proposed method has been successfully applied for determination of tizanidine and orphenadrine in their tablets and ampoules while the ampoules required application of standard addition method as it contains sodium hydroxide which causes significant decrease in the absorbance value [4], Application of standard addition method succeed to remove the interference of additives in the ampoules.

\section{Optimization of experimental conditions}

Factors affecting the complex formation and stability were carefully studied and optimized.

\section{1 - Effect of $\mathrm{pH}$}

The influence of $\mathrm{pH}$ on the absorbance value of the binary complexes was studied over the $\mathrm{pH}$ range 2.6-4.5, Adjustment to $\mathrm{pH} 5$ give negative absorbance values. The optimum absorbance values were obtained at $\mathrm{pH}$ 3.5 for both drugs as shown in Figure 4. Two milliliters of $0.4 \mathrm{M}$ acetate buffer were sufficient to bring the optimum $\mathrm{pH}$ value. For the highest color intensity and maximum precision, the buffer solution should be added after mixing the drug-dye solution at neutral $\mathrm{pH}$.

\section{2 - Effect of concentration of reagent}

The optimum reagent concentration was determined by adding various volumes of $4 \times 10^{-3} \mathrm{M}$ eosin $\mathrm{Y}$ solution. It was found that $1 \mathrm{~mL}$ and $0.7 \mathrm{~mL}$ of the reagent solution for tizanidine and orphenadrine respectively give the highest absorbance values as shown in Figure 5.

\section{3 - Effect of temperature}

The intensity of the final color was maximum at room temperature for both drugs; increasing temperature resulted in formation of a precipitate which may be due to coagulation of the formed complex.

\section{4 - Effect of time}

The formation of the complex was instantaneous and the development of the color was complete within few seconds. The high values of the formation constants $\mathrm{Kf}$ $=2.69 \times 10^{11}$ for tizanidine while for orphenadrine $\mathrm{Kf}=$ $4.77 \times 10^{4}$ reveals high stability of the formed complex, the negative value of $\Delta \mathrm{G}=-6.52 \times 10^{4}$ and $-2.67 \times 10^{4}$ $(\mathrm{KJ} / \mathrm{mole})$ for tizanidine and orphenadrine respectively, points to the spontaneous nature of the reaction [48]. The intensity of the final color was stable for 48 hours with no precipitation of the complex.

\section{Method validation} Linearity and range

The calibration graphs obtained by plotting the absorbance values versus the final concentration were found to be rectilinear over the concentration range cited in table 1. Linear regression analysis of the data gave the following equations:

$$
\begin{aligned}
& \text {-For tizanidine : } \mathrm{A}=0.108+0.124 C \quad(\mathrm{r}=0.9999) \\
& \text {-For orphenadrine }: \mathrm{A}=0.032+0.093 \mathrm{C} \quad(\mathrm{r}=0.9998)
\end{aligned}
$$

Where (A) is the absorbance, $(\mathrm{C})$ is the concentration in $\mu \mathrm{g} / \mathrm{ml}$ and $(\mathrm{r})$ is the correlation coefficient. Statistical analysis of the data gave small values of the standard deviations of the residuals $\left(\mathrm{S}_{\mathrm{y} / \mathrm{x}}\right)$, the standard deviation of the intercept (Sa), the standard deviation of the slope $(\mathrm{Sb})$, and the percentage of relative error (\% Er) as shown in table 1.

\section{Limit of quantification and limit of detection}

The limit of quantification (LoQ) was determined by establishing the least concentration that can be

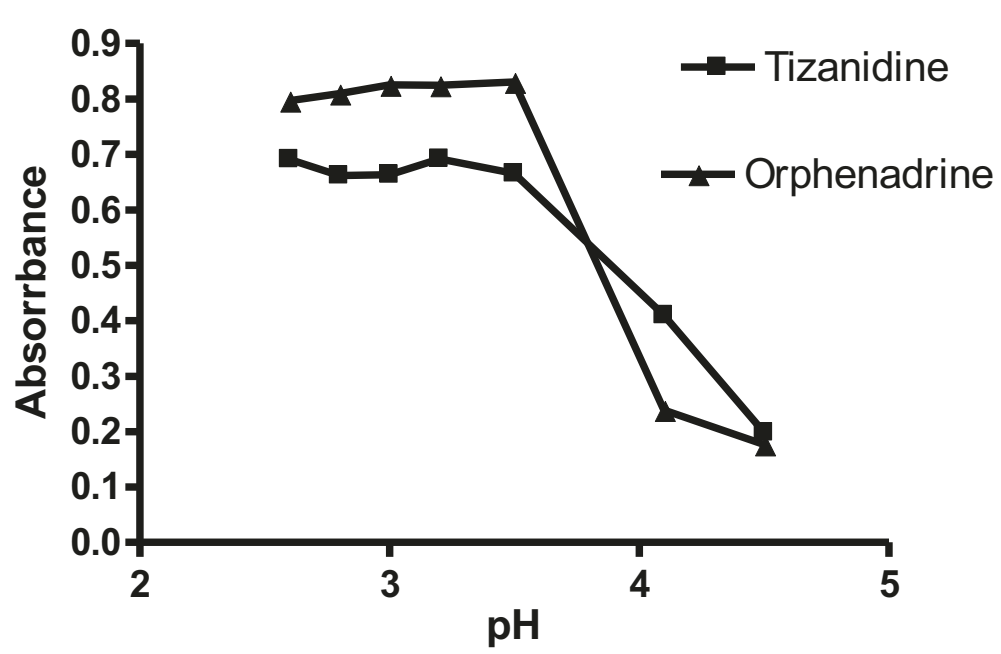

Figure 4 Effect of $\mathrm{pH}$ of $0.4 \mathrm{M}$ acetate buffer on the absorbance of the reaction product of tizanidine or orphenadrine with eosin $\mathrm{Y}(4$ $\times 10^{-3} \mathrm{M}$ ). 


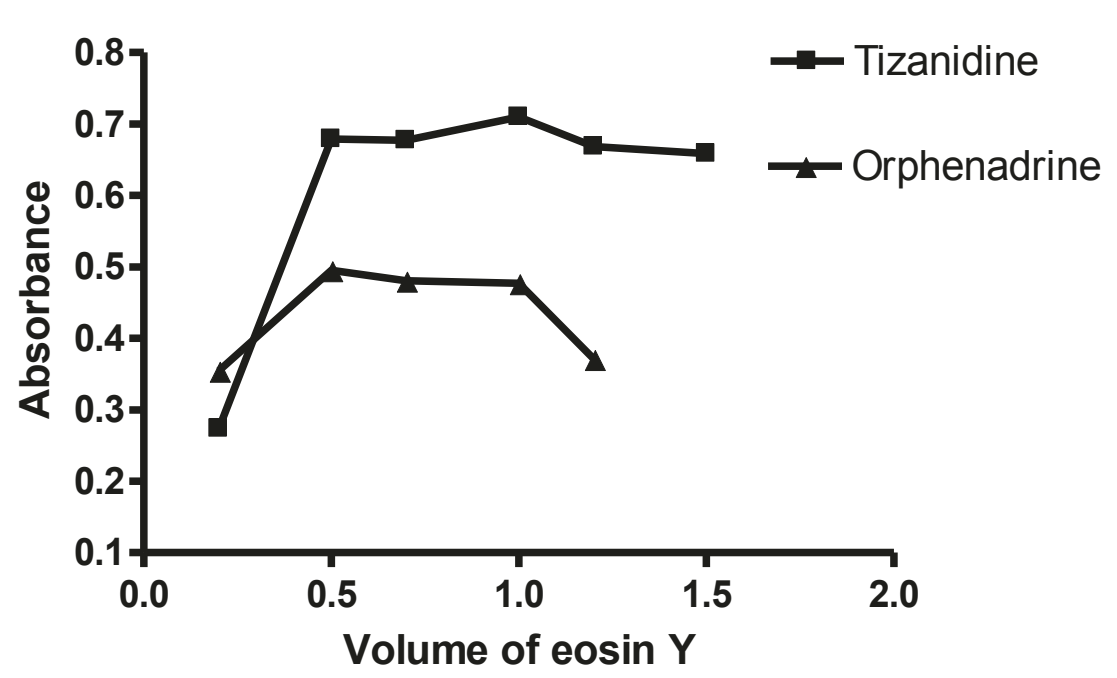

Figure 5 Effect of volume of eosin Yon the absorbance of the reaction product of tizanidine or orphenadrine with eosin $\mathrm{Y}\left(4 \times 10^{-3} \mathrm{M}\right)$

measured according to ICH Q2(R1) recommendations [49], below which the calibration range is non linear, it was found to be $0.27 \mu \mathrm{g} / \mathrm{mL}$ for tizanidine and $0.95 \mu \mathrm{g} /$ $\mathrm{mL}$ for orphenadrine. The limit of detection (LoD) was determined by evaluating the lowest concentration of the analytes that can be readily detected and was found to be 0.1 and $0.3 \mu \mathrm{g} / \mathrm{mL}$ for tizanidine and orphenadrine, respectively. The LoQ and LoD were calculated according to the following equations (ICH 2005):

$$
\begin{aligned}
& \mathrm{LoQ}=10 \mathrm{Sa} / \mathrm{b} \\
& \mathrm{LoD}=3.3 \mathrm{Sa} / \mathrm{b}
\end{aligned}
$$

Where $(\mathrm{Sa})$ is the standard deviation of the intercept of the regression line and (b) is the

slope of the calibration curve.

\section{Accuracy and precision}

To prove the accuracy of the proposed method, the results of the assay of the studied drugs in pharmaceutical preparations were compared with the reference methods [4], the statistical analysis [50] of the results using student's t-test and variance ratio F-test showed no significant differences between them regarding accuracy and precision, tables 2 and 3 .

Intraday and interday precisions were assessed using three concentrations and three replicates of each concentration, the relative standard deviations were found to be very small indicating reasonable repeatability of the proposed method as shown in table 3.

\section{Robustness}

The robustness of the procedure adopted in the proposed method is demonstrated by the constancy of the absorption intensity with minor changes in the experimental parameters such as the change of the $\mathrm{pH}$ of acetate buffer $3.5 \pm 0.2$ for both drugs and volume of eosin $0.7 \pm 0.2$ and $1 \pm 0.5$ for orphenadrine and tizanidine respectively. These minor changes that may take place during the experimental operation did not affect the absorption intensity indicating the excellent robustness of the proposed method.

\section{Specificity}

The specificity of the method was investigated by observing any interference encountered from the common excipients of the pharmaceutical formulations. It was found that these compounds did not interfere with the results of the proposed method as shown in table 2.

\section{Applications}

\section{I - Dosage form analysis}

The proposed method was successfully applied to the assay of tizanidine and orphenadrine in their dosage forms as shown in table 2 . The average percent recoveries of different concentrations were based on the average of three replicate determinations. The results obtained were in good agreement with those obtained by the reference methods [4].

\section{II - Content uniformity test}

Due to the high sensitivity of the proposed method for the determination of tizanidine the content uniformity test was applied. The steps of the test were adopted according to the USP [4] procedures. The acceptance value (AV) was calculated and it was found to be smaller than the maximum allowed acceptance value. The results demonstrated excellent drug uniformity as shown in table 4. 
Table 2 Application of proposed method to the determination of the studied drugs in their dosage forms.

\begin{tabular}{|c|c|c|c|c|c|}
\hline \multirow[t]{2}{*}{ Preparation } & \multicolumn{3}{|c|}{ Proposed method } & \multicolumn{2}{|c|}{ Reference method[4] } \\
\hline & $\begin{array}{l}\text { Conc. added } \\
(\mu \mathrm{g} / \mathrm{mL})\end{array}$ & $\begin{array}{l}\text { Conc. found } \\
(\mu \mathrm{g} / \mathrm{mL})\end{array}$ & Recovery (\%) & $\begin{array}{l}\text { Conc.added } \\
(\mu \mathrm{g} / \mathrm{mL})\end{array}$ & Recovery(\%) \\
\hline Sirdalud $^{\circledR}$ tablets & 2.0 & 2.02 & 101.00 & 40.0 & 99.40 \\
\hline \multirow[t]{2}{*}{ (2 mg tizanidine hydrochloride/tablet) } & 4.0 & 3.98 & 99.50 & 80.0 & 100.50 \\
\hline & 8.0 & 8.03 & 100.37 & 100.0 & 100.60 \\
\hline$\overline{\mathrm{X}} \pm \mathrm{SD}$ & \multicolumn{3}{|c|}{$100.29 \pm 0.75$ (found amount $=2.005 \mathrm{mg} /$ tablet $)$} & \multicolumn{2}{|c|}{$100.20 \pm 0.66$} \\
\hline $\mathrm{t}$ & \multicolumn{3}{|c|}{$0.21(2.77)$} & & \\
\hline $\mathrm{F}$ & \multicolumn{3}{|c|}{$1.28(19)$} & & \\
\hline Sirdalud $^{\circledR}$ tablets & 2.0 & 2.03 & 101.5 & 40.0 & 99.90 \\
\hline \multirow{2}{*}{ (4 mg tizanidine hydrochloride/tablet) } & 4.0 & 4.00 & 100.00 & 80.0 & 98.50 \\
\hline & 8.0 & 7.96 & 99.50 & 100.0 & 100.20 \\
\hline $\bar{X} \pm S D$ & \multicolumn{3}{|c|}{$100.33 \pm 1.04$ (found amount $=4.013 \mathrm{mg} /$ tablet $)$} & \multicolumn{2}{|c|}{$99.53 \pm 0.91$} \\
\hline $\mathbf{t}$ & \multicolumn{3}{|c|}{$1.00(2.77)$} & & \\
\hline $\mathbf{F}$ & \multicolumn{3}{|c|}{$1.31(19)$} & & \\
\hline \multirow[t]{3}{*}{ Norflex ${ }^{\circledR}$ tablets (100 mg orphenadrine citrate/tablet) } & 5.0 & 4.99 & 99.90 & 20.0 & 98.79 \\
\hline & 10.0 & 9.87 & 98.70 & 50.0 & 100.55 \\
\hline & 12.0 & 12.11 & 100.90 & 100.0 & 98.99 \\
\hline$\overline{\mathrm{X}} \pm \mathrm{SD}$ & \multicolumn{3}{|c|}{$99.83 \pm 1.10$ (found amount $=99.83 \mathrm{mg} /$ tablet $)$} & \multicolumn{2}{|c|}{$99.44 \pm 0.96$} \\
\hline $\mathbf{t}$ & \multicolumn{3}{|c|}{$0.46(2.77)$} & & \\
\hline $\mathrm{F}$ & \multicolumn{3}{|c|}{$1.31(19)$} & & \\
\hline \multirow[t]{3}{*}{ Norflex ${ }^{\circledR}$ ampoules (30 mg orphenadrine citrate $/ \mathrm{mL}$ ) } & 3.0 & 2.95 & 98.30 & 20.0 & 98.76 \\
\hline & 5.0 & 5.10 & 102.00 & 50.0 & 98.00 \\
\hline & 10.0 & 10.07 & 100.70 & 100.0 & 100.30 \\
\hline$\overline{\mathrm{X}} \pm \mathrm{SD}$ & \multicolumn{3}{|c|}{$100.33 \pm 1.87$ (found amount $=30.099 \mathrm{mg} / \mathrm{mL}$ ) } & \multicolumn{2}{|c|}{$99.02 \pm 1.17$} \\
\hline $\mathbf{t}$ & \multicolumn{3}{|c|}{$1.03(2.77)$} & & \\
\hline $\mathrm{F}$ & \multicolumn{3}{|c|}{2.56 (19) } & & \\
\hline
\end{tabular}

*Note. Each result is the average of three separate assays.

*Values between brackets are the tabulated $t$ and $F$ values at $p=0.05$

Table 3 Accuracy and precision data for the studied drugs using the proposed method.

\begin{tabular}{|c|c|c|c|c|c|c|}
\hline \multicolumn{7}{|c|}{ Tizanidine } \\
\hline \multirow[t]{2}{*}{ Parameter } & \multicolumn{3}{|c|}{ Intra-day precision } & \multicolumn{3}{|c|}{ Inter-day precision } \\
\hline & $\begin{array}{c}\text { Concentration taken } \\
(\mathrm{mg} / \mathrm{mL})\end{array}$ & $\begin{array}{c}\text { Concentration found } \\
(\mathrm{mg} / \mathrm{mL})\end{array}$ & $\%$ Found & $\begin{array}{c}\text { Concentration taken } \\
(\mathrm{mg} / \mathrm{mL})\end{array}$ & $\begin{array}{c}\text { Concentration found } \\
(\mathrm{mg} / \mathrm{mL})\end{array}$ & $\%$ Found \\
\hline \multirow[t]{3}{*}{ Data } & 2.0 & 2.02 & 101.00 & 2.0 & 2.01 & 100.50 \\
\hline & 4.0 & 3.99 & 99.83 & 4.0 & 4.003 & 100.10 \\
\hline & 8.0 & 7.9 & 99.62 & 8.0 & 7.99 & 99.90 \\
\hline $\bar{X} \pm S D$ & \multicolumn{3}{|c|}{$100.15 \pm 0.74$} & \multicolumn{3}{|c|}{$100.20 \pm 1.28$} \\
\hline$\%$ RSD & \multicolumn{3}{|c|}{0.74} & \multicolumn{3}{|c|}{1.3} \\
\hline \%Error & \multicolumn{3}{|c|}{0.43} & \multicolumn{3}{|c|}{0.75} \\
\hline \multicolumn{7}{|c|}{ Orphenadrine } \\
\hline \multirow[t]{2}{*}{ Parameter } & \multicolumn{3}{|c|}{ Intra- day precision } & \multicolumn{3}{|c|}{ Inter- day precision } \\
\hline & $\begin{array}{c}\text { Concentration taken } \\
(\mathrm{mg} / \mathrm{mL})\end{array}$ & $\begin{array}{c}\text { Concentration found } \\
(\mathrm{mg} / \mathrm{mL})\end{array}$ & $\%$ Found & $\begin{array}{c}\text { Concentration taken } \\
(\mathrm{mg} / \mathrm{mL})\end{array}$ & $\begin{array}{c}\text { Concentration found } \\
(\mathrm{mg} / \mathrm{mL})\end{array}$ & $\%$ Found \\
\hline \multirow[t]{3}{*}{ Data } & 3.0 & 2.99 & 99.66 & 3.0 & 2.97 & 99.00 \\
\hline & 5.0 & 4.99 & 99.86 & 5.0 & 5.01 & 100.20 \\
\hline & 12.0 & 12.08 & 100.66 & 12.0 & 12.02 & 100.16 \\
\hline $\bar{X} \pm S D$ & \multicolumn{3}{|c|}{$100.06 \pm 0.53$} & \multicolumn{3}{|c|}{$99.78 \pm 0.68$} \\
\hline$\%$ RSD & \multicolumn{3}{|c|}{0.53} & \multicolumn{3}{|c|}{0.68} \\
\hline \%Error & \multicolumn{3}{|c|}{0.31} & \multicolumn{3}{|c|}{0.39} \\
\hline
\end{tabular}

(a) Each result is the average of three separate experiments

$\overline{\mathrm{X}}=$ The mean recovery; SD Standard deviation of results. 
Table 4 Results of content uniformity testing of Sirdalud ${ }^{\circledR}$ tablets using the proposed method.

\begin{tabular}{cc}
\hline Percentage of the label claim & Parameter \\
\hline Tablet No.1 & 101.24 \\
Tablet No.2 & 97.39 \\
Tablet No.3 & 100.42 \\
Tablet No.4 & 98.45 \\
Tablet No.5 & 100.69 \\
Tablet No.6 & 98.13 \\
Tablet No.7 & 97.21 \\
Tablet No.8 & 99.87 \\
Tablet No.9 & 99.96 \\
Tablet No.10 & 100.51 \\
\hline Mean ( $\bar{X})$ & 99.38 \\
S.D. & 1.46 \\
\% RSD & 1.46 \\
\% Error & 0.46 \\
Acceptance value(AV)(4) & 3.5 \\
Max. Allowed value(LI)(4) & 15 \\
\hline
\end{tabular}

\section{Conclusion}

A Simple, sensitive, fast, accurate and precise spectophotometric method was developed for the determination of tizanidine and orphenadrine in their pharmaceutical formulations with limit of quantification of $0.26 \mu \mathrm{g} / \mathrm{mL}$ for tizanidine and $0.95 \mu \mathrm{g} / \mathrm{mL}$ for orphenadrine. Eosin $\mathrm{Y}$ was chosen as an ion-pairing agent with the aim of obtaining stable and water soluble ion pairs whose absorbance would be measured accurately. The advantage of the method being less time consuming and do not require various elaborate treatments and tedious extraction procedures, In addition to the satisfactory sensitivity and reproducibility as well as the convenience and simplicity.

\section{Authors' contributions}

MIW designed the proposed method and analyzed the data statistically. FFB proposed, planned and supervised the whole work. MIE coordinated the study and modified the text. SAE carried out the experimental work. All authors read and approved the final manuscript.

\section{Competing interests}

The authors declare that they have no competing interests.

Received: 10 July 2011 Accepted: 8 October 2011

Published: 8 October 2011

\section{References}

1. Sweetman S: Martindale The Complete Drug Reference. 35 edition. The Pharmaceutical Press, London; 2007, 1738

2. Budavari S: The Merck Index on CD-Room. By Merck\& Co., Inc., White House Station, $\mathrm{NJ}_{\text {i, }} 121996$

3. Moffat AC, Osselton MD, Widdop B: Clarkes Analysis of Drugs and Poisons. 3 edition. Pharmaceutical Press, London; 2004, 1371, 1641

4. The United States Pharmacopoeia 30, the National Formulary 25, US Pharmacopeial Convention: Rockville, MD. 2007, Electronic version.
5. Shankar MB, Shah DA, Geetha M, Mehta FA, Mehta RS, Bhatt KK: Simultaneous spectrophotometric determination of tizanidine and diclofenac in tablets. Ind J Pharm Sci 2004, 66:332-336.

6. Dahiya $R$, Chaudhary $H$, Rathee $P$, Nagori BP: Spectrophotometric method for the estimation of tizanidine in bulk and tablet dosage forms. Indian Pharmacist 2008, 7:59-62.

7. Dashora K, Gopal G, Saraf S, Swarnlata S: Spectrophotometric determination of aceclofenac and tizanidine hydrochloride. Asian J Chem 2007, 19:3289-3291.

8. Ashok K, Kumar R, Anroop B, Tuli k, Gupta AK: Spectrophotometric method for estimation of rofecoxib and tizanidine hydrochloride in tablets. Indian Pharmacist 2007, 6:61-64.

9. Prabhakar B, Manjunath K, Shobha R, Appala S: Development and validation of spectrophotometric methods for the estimation of tizanidine in pharmaceutical dosage forms. J Ind Council Chem 2005, 22:37-41.

10. Reddy T, Rama S, Rao SV, Murali M, Rao AN, Sastry CSP: Simple spectrophotometric methods for the determination of tizanidine. J Ind Council Chem 2003, 20:26-29.

11. Dashora K, Saraf S, Saraf S: Simultaneous spectrophotometric method for the determination of nimesulide and tizanidine hydrochloride. Oriental J Chem 2006, 22:167-168.

12. Sivasubramanian L, Devarajan : Spectrophotometric and HPLC methods for simultaneous estimation of tizanidine and valdecoxib from tablets. Int J ChemTech Res 2009, 1:96-102.

13. Kauffmann JM, Ruiz BL, Gotor MF, Patriarche GJ: Electrochemical behaviour of tizanidine at solid electrodes. J Pharm Biomed Anal 1992, 10:763-767.

14. Tuncel M, Dogrukol D: Study on the polarographic behaviour and determination of tizanidine. Anal Lett 1992, 25:1087-1094.

15. Bouklouze AA, El Jammal A, Vire JC, Patriarche GJ: Comparative study of three polymeric membrane electrodes selective to tizanidine. Anal Chim Acta 1992, 257:41-48

16. Gunnar T, Mykkanen S, Ariniemi K, Lillsunde P: Validated semiquantitative/ quantitative screening of 51 drugs in whole blood as silylated derivatives by gas chromatography-selected ion monitoring mass spectrometry and gas chromatography electron capture detection. $J$ Chromatogr B 2004, 806:205-219.

17. Lee J, Seo JH, Kim DY: Determination of tizanidine in human plasma by gas chromatography- mass spectrometry. Analyst 2002, 127:917-920.

18. Kaul N, Dhaneshwar SR, Agrawal H, Kakad A, Patil B: Application of HPLC and HPTLC for the simultaneous determination of tizanidine and rofecoxib in pharmaceutical dosage form. J Pharm Biomed Anal 2005, 37:27-38.

19. Mahadik KR, Paradkar AR, Agrawal H, Kaul N: Stability indicating HPTLC determination of tizanidine hydrochloride in bulk drug and pharmaceutical formulations. J Pharm Biomed Anal 2003, 33:545-552.

20. Pawar UD, Sulebhavikar AV, Naik AV, Pingale SG, Mangaonkar KV: Simultaneous determination of rofecoxib and tizanidine by HPTLC. E J Chem 2009, 6:295-302.

21. Gandhimathi M, Ravi TK, Varghese SJ: Simultaneous LC determination of tizanidine and rofecoxib in tablets. J Pharm Biomed Anal 2005, 37:183-185.

22. Qi ML, Wang P, Wang L: Validated liquid chromatography method for assay of tizanidine in drug substance and formulated products. Anal Chim Acta 2003, 478:171-178

23. Raman B, Patil D: Reversed phase HPLC for simultaneous estimation of tizanidine and nimesulide in tablets. Indian Drugs 2002, 39:392-394.

24. Bhoir IC, Raman B, Sundaresan M, Bhagwat AM: Development of an isocratic SFC method for four centrally active muscle relaxant drugs. Anal Lett 1998, 31:1533-1542.

25. The British Pharmacopoeia 2007. The Stationery Office: London; Electronic version; 2007.

26. Sane RT, Mishra PD, Ladage KD, Kothurkar RM, Joshi LS: Extractive colorimetric method for the determination of orphenadrine hydrochloride from pharmaceutical preparations. Indian Drugs 1989, 26:719-721.

27. Shama SA: Spectrophotometric determination of phenylephrine hydrochloride and orphenadrine citrate in pure and in dosage forms. $J$ Pharm Biomed Anal 2002, 30:1385-1392.

28. Elnemma EM, El Zawawy FM, Hassan SSM: Determination of amitriptyline, imipramine and orphenadrine in antidepressant drugs by 
potentiometry, spectrophotometry and atomic absorption spectrometry. Mikrochim Acta 1993, 110:79-88.

29. Saleh HM, EL-Henawee MM, Ragab GH, Abd El-Hay SS: Utility of NBD-Cl for the spectrophotometric determination of some skeletal muscle relaxant and antihistaminic drugs. Spectrochimica Acta Part A 2007, 67:1284-1289.

30. El-Din MKS, Abuirjeie MA, Abdel-Hay MH: Simultaneous determination of acetaminophen(paracetamol) with orphenadrine citrate, ibuprofen or chlorzoxazone in combined dosage forms by zero crossing derivative spectrophotometry. Anal Lett 1991, 24:2187-2206.

31. Contin M, Riva R, Albani F, Baruzzi A: Simple and rapid GLC for the determination of orphenadrine in human plasma. Biomed. Chromatogr 1987, 2:193-194.

32. Koppenhoefer B, Jakob A, Zhu XF, Lin BC: Separation of enantiomers of drugs by capillary electrophoresis with permethyl-gamma-cyclodextrin as chiral solvating solvent. J High Resolut Chromatogr 2000, 23:413-429.

33. Tang YF, Wu HL, Wu SM, Chen SH, Kou HS: Quantitative chiral analysis of carbinoxamine, doxylamine and orphenadrine by capillary zone electrophoresis. J Microcolumn Sep 2000, 12:366-370.

34. Koppenhoefer B, Epperlein U, Christian B, Ji YB, Chen YY, Lin BC, Bingcheng $L$ : Separation of enantiomers of drugs by capillary electrophoresis: gamma cyclodextrin as chiral solvating agent. J Chromatogr A 1995, 717:181-190.

35. Lin BC, Ji YB, Chen YJ, Epperlein U, Koppenhoefer B: Separation of drug enantiomers by capillary electrophoresis: alpha-cyclodextrin as chiral solvating agent. Chromatographia 1996, 42:106-110.

36. Sheikh-Salem MA, Alkaysi HN, Gharaibeh AM: Quantitation of orphenadrine citrate and acetaminophen [paracetamol] in tablet formulation using thin-layer chromatography-densitometry. Anal Lett 1989, 22:585-596.

37. Lee SY, Oh HJ, Kim JW, Kim YG, Moon CJ, Lee EH: Pharmacokinetic study of orphenadrine using high performance liquid chromatography-tandem mass spectrometry (HPLC-MS/MS). J Chromatogr B 2006, 839:118-123.

38. Al-Kaysi HN, Salem MAS: High pressure liquid chromatographic analysis of orphenadrine citrate and acetaminophen [paracetamol] in pharmaceutical dosage forms. Anal Lett 1987, 20:1451-1466.

39. Selkirk SM, Fell AF, Smith G, Miller JHM: Stability-indicating assay for orphenadrine hydrochloride by reversed phase high performance liquid chromatography. J Chromatogr 1984, 288:431-444.

40. El-Walily AFM, Belal SF, Bakry RS: Spectrophotometric and spectrofluorimetric estimation of ciprofloxacin and norfloxacin by ternary complex formation with eosin and palladium(II). J Pharm Biomed Anal 1996, 14:561-569.

41. El-Enany N: Spectrophotometric determination of gliclazide in pharmaceuticals and biological fluids through ternary complex formation with eosin and palladium(II). IL Farmaco 2004, 59:63-69.

42. El-Brashy AM, Metwally MES, El-Sepai FA: Spectrophotometric determination of fluoroquinolone antibacterials by binary complex formation with xanthene dyes. IL Farmaco 2004, 59:809-817.

43. Walash MI, El-Brashy AM, Metwally MES, Abdelal AA: Fluorimetric determination of ethionamide in pharmaceutical preparations and biological fluids. J Chin Chem Soc 2004, 51:1059-1064.

44. Walash MI, Rizk MS, Eid MI, Fathy ME: Spectrophotometric determination of four macrolide antibiotics in pharmaceutical formulations and biological fluids via binary complex formation with eosin. $J A O A C$ International 2007, 90:1579-1587.

45. Omar MA: Spectrophotometric and spectrofluorimetric determination of certain diuretics through ternary complex formation with eosin and lead (II). J Fluorescence 2009, 20:275-281.

46. Rose J: Advanced Physicochemical Experiments Pitman: London, England; $1964,67$.

47. Chernov'yants MS, Podgornaya EB, Chernyshev AV, Metelitsa AV, knyazhznskii MO: Identification and extraction-spectrophotometric and or extraction-fluorimetric determination of organic nitrogen-containing triiodides, new biologically active compounds. J Anal Chem 2000, 55:245-248.

48. Inczedy J: Analytical Applications of Complex Equilibria John Wiley \& Sons, Budapest; 1976, 101

49. ICH Harmonized Tripartite Guideline: Validation of Analytical Procedures. Text and Methodology, Q2(R1). 2005 [http://www.bioforum.org.il/Uploads/ Editor/karen/q2_r1_step4.pdf], Current Step 4 Version, Parent Guidelines on methodology.
50. Miller JN, Miller JC: Statistics and Chemometrics for Analytical Chemistry. 5 edition. Pearson Education Limited, Harlow; 2005.

doi:10.1186/1752-153X-5-60

Cite this article as: Walash et al: Spectrophotometric determination of tizanidine and orphenadrine via ion pair complex formation using eosin Y. Chemistry Central Journal 2011 5:60.

\section{Publish with ChemistryCentral and every scientist can read your work free of charge \\ "Open access provides opportunities to our colleagues in other parts of the globe, by allowing anyone to view the content free of charge." \\ W. Jeffery Hurst, The Hershey Company.}

- available free of charge to the entire scientific community

- peer reviewed and published immediately upon acceptance

- cited in PubMed and archived on PubMed Central

- yours - you keep the copyright

Submit your manuscript here:

http://www.chemistrycentral.com/manuscript/<smiles>c1ccccc1</smiles>

Chemistry Central 